\title{
New Antimicrobial and Biocompatible Implant Coating with Synergic Silver-Vancomycin Conjugate Action
}

\author{
Massimo Varisco, ${ }^{[a]}$ Nina Khanna, ${ }^{[b]}$ Priscilla S. Brunetto, ${ }^{*[a]}$ and Katharina M. Fromm ${ }^{*[a]}$
}

\begin{abstract}
Materials foreign to the body are used ever more frequently, as increasing numbers of patients require implants. As a consequence, the numbers of implant-related infections have grown as well, and with increasing resistance. Treatments often fail; thus, new antibacterial coating strategies are being developed by scientists to avoid, or at least strongly reduce, bacterial adhesion to implant surfaces. In this study, we focused on producing a self-protective coating combining silver $(\mathrm{I})$ ions and a vancomycin-derived molecule, intelligent pyridinate vanco-
\end{abstract}

mycin (IPV), with a synergetic and effective action against bac teria. These Ag'-IPV conjugate-coated surfaces are well characterized and exhibit strong bactericidal activity in vitro against Staphylococci strains. Furthermore, the released quantities of both drugs from the coated surfaces do not affect their biocompatibility and soft tissue integration. These newly developed $\mathrm{Ag}^{\prime}-\mathrm{IPV}$ conjugate coatings thus represent a possible and efficient protection method against bacterial adhesion and biofilm formation during and after implant surgery.

\section{Introduction}

Biomaterials are used increasingly more frequently in modern medicine subsequent to trauma or oncological surgery, or to replace or restore human body function; for example, in hip prostheses, prosthetic heart valves, or catheters. However, the landscape of clinical infections related to medical devices is continuously changing and poses a serious public health threat. Treatment of biomaterial-related infections is complicated, as microorganisms in a biofilm are more resistant to antibiotics ${ }^{[1]}$ than their planktonic counterparts. ${ }^{[2]}$ Currently, the only effective treatment is to remove the infected implant and tissue, fight the infection with antibiotics, and replace the implant-a long, costly, and stressful procedure. ${ }^{[1,3]}$ A more convenient way to deal with this problem is to prevent, or at least diminish, the development of an infectious biofilm on the biomaterial surface by creating bactericidal surfaces. Researchers have found a way to covalently bind the well-known vancomycin antibiotic to the surface of titanium via organosilane covalent bonds at the $\mathrm{Ti}-\mathrm{OH}$ surface of the metal ${ }^{[4-7]}$ or via a poly(ethylene glycol) substituted anachelin at the $\mathrm{TiO}_{2}$ surface, ${ }^{[8]}$ demonstrating that vancomycin remained active. However, the main concern with purely antibiotic coatings is the development of bacterial resistance. ${ }^{[9,10]}$ To overcome this problem, scientists are developing effective new coating strategies, such as nanoparticle-antibiotic conjugates, as it has been found that

[a] M. Varisco, Dr. P. S. Brunetto, Prof. Dr. K. M. Fromm

Department of Chemistry, University of Fribourg

Chemin du Musée 9, 1700 Fribourg (Switzerland)

E-mail: priscilla.brunetto@unifr.ch

katharina.fromm@unifr.ch

[b] Dr. N. Khanna

Department of Biomedicine, University Hospital Basel Hebelstrasse 20, 4031 Basel (Switzerland)

Supporting information for this article is available on the WWW under http://dx.doi.org/10.1002/cmdc.201400072. nanoparticles of silver and copper are active against bacteria and fungi. ${ }^{[11-14]}$ Indeed, metal ions are known to accelerate and enhance drug actions and efficacy against resistant pathogens. ${ }^{[15-17]}$

Vancomycin (VAN) has traditionally been reserved as a drug of last resort, used only when treatment with other antibiotics has failed. It is the archetypal member of the family of glycopeptide antibiotics that includes such compounds as teicoplanin, ristocein, and avoparcin. ${ }^{[18]}$ VAN is a narrow-spectrum antibiotic active against Gram-positive bacteria. As is well-known, VAN inhibits glycan polymerization and/or crosslinking by binding to the substrate of transglycosylase and transpeptidase enzymes responsible for the reticulation of the growing peptidoglycan cell wall. ${ }^{[19,20]}$ This leaves the cell susceptible to lysis, due to changes in osmotic pressure.

Silver is one of the so-called "heavy metals" that remains non-toxic to humans. ${ }^{[21]}$ For thousands of years, silver has been used as a healing and antibacterial agent by civilizations throughout the world. ${ }^{[22,23]}$ The antimicrobial activity of silver ions was first identified in the 19th century and has found a variety of applications, but silver lost its medical status with the introduction of antibiotics, the so-called "miracle drugs". Due to the development of antibiotic-resistant strains, silver was reintroduced in 20th century medicine in a wide variety of forms, showing strong biocidal effect against microorganisms. ${ }^{[24]}$ It was first used in a salt form ${ }^{[25]}$ and then in combination with sulfonamide antibiotics, such as silver sulfadiazine (SSD), which continues to be prescribed primarily for the management of burn wounds. ${ }^{[26]}$ Unlike antibiotics, which are specific only to bacteria, silver ions and silver nanoparticles kill germs of all major types: Gram-positive and Gram-negative bacteria, ${ }^{[27-30]}$ fungi/yeasts, ${ }^{[31,32]}$ and viruses. ${ }^{[33-36]}$ Many proposed mechanisms regarding the antibacterial effect of silver ions, such as interaction with the bacterial cell membrane, in- 
terference with electron transport, and binding to DNA, have been presented. ${ }^{[11,13-16,22,37-40]}$

The present research focuses on a newly synthesized AgVAN derivative conjugate as a target for attachment to the surface of implant materials. Indeed, combinations of VAN and silver are expected to be synergistic with respect to practical effectiveness. Coated surfaces were characterized, tested for their antimicrobial efficacy against Gram-positive bacteria, and evaluated for their biocompatibility for soft tissue integration.

\section{Results and Discussion}

\section{Product synthesis}

We have shown previously that silver coordination polymers, based on silver ions and an innocent ligand, can be used as efficient antimicrobial and biocompatible implant coatings. ${ }^{[41-46]}$ The ligand used was derived from nicotinic acid and polyethylene glycol and allowed coordination to silver ions via nitrogen atoms without showing toxicity towards fibroblast cell lines. In order to integrate the VAN into such an implant surface coating (Figure 1) without loss of function, chemical modification of the molecule was necessary. As it is known that the VAN $C$ terminus is not essential for its activity, ${ }^{[47-49]}$ the carboxylic acid group was chosen for covalent coupling to a pyridinyl group via a linker, as pyridine possesses a good coordination site to bind silver ions. Thus, the new VAN derivative, intelligent pyridinate vancomycin (IPV), was prepared by HATUmediated coupling reactions (Scheme 1) in which [2-(2-(Fmocamino)ethoxy)ethoxy]acetic acid was functionalized by addi-

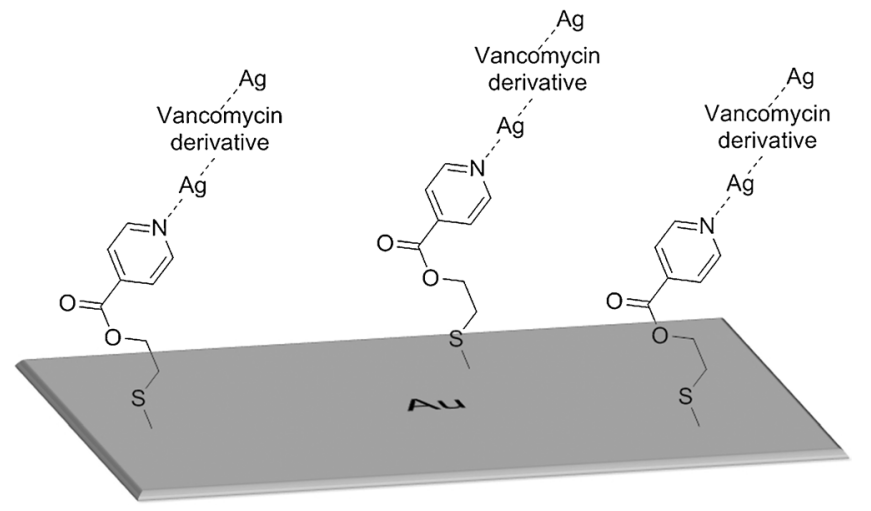

Figure 1. Representation of the coating on an $A u(111)$ surface, containing the sulfur anchor molecule, a first silver(I) ion layer, and IPV, a derivative of vancomycin, complexed to a second silver(I) ion.

tion of a pyridinyl group, followed by Fmoc deprotection. A further coupling reaction with the carboxylic acid of the VAN molecule afforded the final crude product, which was subsequently purified by reverse-phase HPLC.

\section{Product analysis}

The ${ }^{1} \mathrm{H}$ NMR spectrum (Supporting Information) shows the peaks expected for the pyridinyl group and the flexible hydrophilic linker, and electrospray ionization mass spectrometry (ESI-MS) revealed the expected ion at $\mathrm{m} / \mathrm{z}$ 1671.55. As it is known that VAN decomposes at $40{ }^{\circ} \mathrm{C}^{[50]}$ the differential scanning calorimetry results (Supporting Information) of both IPV

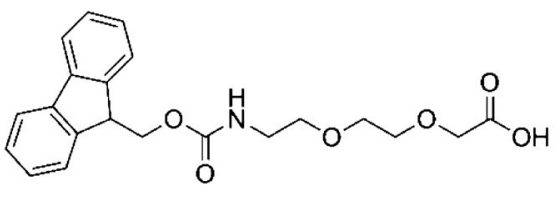

1

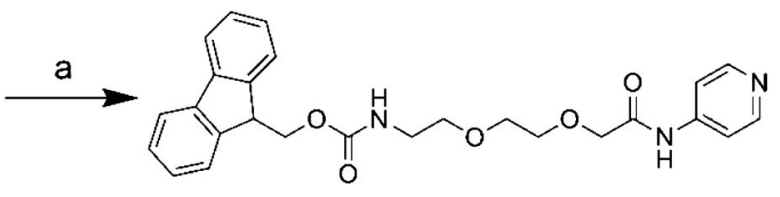

2<smiles>CC[123I]</smiles>

C<smiles>C=C(Cl)COC1O[C@H](O)[C@@H](O[C@H]2C[C@](C)(N)[C@@H](O)[C@H](C)O2)[C@H](O)[C@@H]1O</smiles>

Scheme 1. Synthetic strategy used to convert VAN to IPV. Reagents and conditions: a) 4-aminopyridine, HATU and DIEA, DMF, $2^{\circ} \mathrm{C}, 15 \mathrm{~h}$; b) piperidine, DMF, RT, $5 \mathrm{~h}$; c) vancomycin, HATU and DIEA, DMF, $2{ }^{\circ} \mathrm{C}, 15 \mathrm{~h}, 25 \%$ over 3 steps. 
and VAN was recorded. Both molecules have the same decomposition temperature (around $35-40{ }^{\circ} \mathrm{C}$ ), proving that the new antibiotic derivative is as available and stable as VAN.

UV-visible spectroscopy was chosen to follow the evolution of the system until its final coating. Upon functionalization of VAN to yield IPV, the characteristic signal of VAN at $270 \mathrm{~nm}$ was slightly shifted to $280 \mathrm{~nm}$, with an additional new signal at $220 \mathrm{~nm}$. This signal corresponds to the newly introduced pyridinyl group and increases upon addition of $\mathrm{AgNO}_{3}$, suggesting that the complexation between IPV and silver(I) ions takes place at this site.

The complexation of silver ions by VAN and IPV has been also studied using ESI-MS. The mass spectra of the silver complexes of Ag'-VAN and Ag'-IPV contained multiple peaks stemming from the ionizations of metal complexes, free ligands, and related molecular fragments (Supporting Information). For VAN, the most frequently formed complex was the $\left[\mathrm{VAN}+1 \mathrm{Ag}+1 \mathrm{H}^{+}\right]$at $\mathrm{m} / \mathrm{z} 1556.38\left(1: 1\right.$ ratio of VAN and $\left.\mathrm{Ag}^{+}\right)$. However, two silver ions were found to be coordinated by the derivative IPV to form two complexes, $\left[\mathrm{IPV}+1 \mathrm{Ag}+1 \mathrm{H}^{+}\right]$and $[\mathrm{IPV}+2 \mathrm{Ag}+\mathrm{H}]^{+}$, exhibiting ions at $\mathrm{m} / \mathrm{z} 1777.40$ and 1885.33 , respectively. Related molecular fragments for both VAN and IPV also formed complexes with silver $\mathrm{Ag}^{+}$, as VAN and IPV lost their sugar moieties to form the aglycon structures aVAN and aIPV in the gas phase. These complexes, [aVAN $+1 \mathrm{Ag}+1 \mathrm{H}^{+}$], $\left[\mathrm{alPV}+1 \mathrm{Ag}+1 \mathrm{H}^{+}\right]$, and $\left[\right.$alPV $\left.+2 \mathrm{Ag}+1 \mathrm{H}^{+}\right]$, exhibit ions at $\mathrm{m} / \mathrm{z}$ 1251.18, 1472.27, and 1583.38, respectively (Supporting Information). From these data, we assumed that the only binding site for Ag' in VAN is located in the peptide core of the molecule. Also, UV-Vis and ESI-MS show that IPV apparently contains two different binding sites for $\mathrm{Ag}^{\prime}$ ions, one that is expected to be the same as for VAN in the peptide core, and a second coordination site that is located at the pyridinyl group. Crystals of VAN and IPV containing silver(I) ions were not until now, despite our extensive trials. We also tried to simulate the $3 D$ structure using a heteronuclear two-dimensional NMR technique, but the poor resolution of ${ }^{1} \mathrm{H}-{ }^{15} \mathrm{~N}$ HSQC (heteronuclear single quantum coherence) spectra did not allow any conclusion at this point.

\section{Coating}

In order to study the attachment of our coating, an oriented gold $\mathrm{Au}(111)$ layer was used as a model surface. This is a reproducible surface, which guarantees the reliability of our measurements. In our previous antimicrobial coatings studies, ${ }^{[41-43]}$ a sulfur-containing molecule with a pyridinyl group was synthesized $^{[51]}$ as a surface linker, as it is known that the sulfur atom forms a covalent bond with the gold atoms. This disulfide precursor (BriSSBri) of the anchor molecule (SBri) acted as the starting point to build up the silver-coated surfaces. Such antimicrobial coatings were obtained either by direct coating or in a layer-by-layer deposition of the coating components, namely silver ions and ligand. ${ }^{[41,42,44]}$

In this study, a layer-by-layer method was preferred. After being flame-annealed, the gold plates were treated with the disulfide precursor and then immersed in a silver(I) nitrate solu- tion to generate the first silver layer. In order to obtain the final coating (Figure 1), a combined treatment using both IPV and silver(I) nitrate was performed to produce the final coated surface. An uncoated $\mathrm{Au}(111)$ surface (1) served as a control, and two active surface coatings were prepared. A first coating (2) was obtained by depositing the SBri linker, followed by a layer of silver nitrate and a final coating of IPV (Au(111)-SBriAg-IPV). For the second active sample, the deposition sequence was the same except for the last coating solution, which contained an IPV-Ag complex, yielding Au(111)-SBri-Ag[IPV-Ag] (3).

\section{Surface analysis}

To determine the presence and distribution of IPV attached to $\mathrm{Au}(111)$, indirect immunofluorescence detection of the Ag'-IPV conjugate was performed with a specific anti-VAN antibody, as shown in Figure 2. In Figure $2 \mathrm{~A}$, the uncoated control surface of type 1 showed no fluorescence. In Figure $2 B$, the intermediate coated surfaces (2) showed a diffuse fluorescence with few small aggregates.
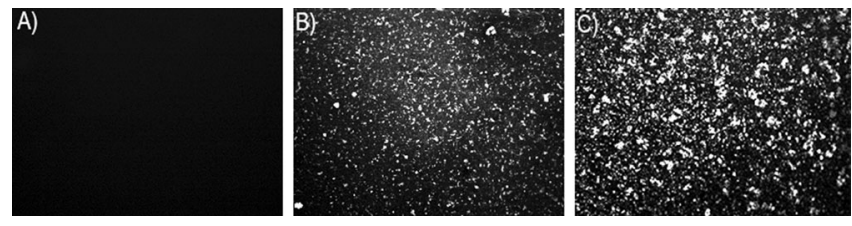

Figure 2. Immunofluorescence detection of vancomycin derivative IPV on gold surfaces. Gold surfaces were incubated with anti-vancomycin antibody for $24 \mathrm{~h}$, followed by incubation with an FITC-coupled secondary antibody before being analyzed under a confocal microscope. A) uncoated $\mathrm{Au}(111)$ surface 1 (magnification $20 \times$ ). B) coated Au(111)-SBri-Ag-IPV surface 2 (magnification $20 \times$ ). C) Au(111)-SBri-Ag-IPV-[IPV-Ag] surface 3 (magnification 20 $\times)$.

These findings indicated that our coating was homogenous, with minor irregularities. The final coated surfaces (3) (Figure $2 \mathrm{C}$ ) show a stronger fluorescence with aggregate formation. As expected, overall fluorescence detection increases as the IPV is increasingly coated, indicating the formation of an IPV-containing coating. Controls made by omitting the disulfide anchor and the first silver layer did not show any green fluorescence (data not shown here), leading to the conclusion that IPV is connected to the surface, mediated by coordination to silver ions which are themselves bound to the $A u$ surface via the sulfur-containing SBri linker (as demonstrated earlier). ${ }^{[40,41,43]}$ These data demonstrate that pyridinyl derivatization of VAN provides an efficient linker between silver and the VAN moiety of IPV, and that the surface can be covered evenly with areas of focal concentrations, likely with multiple layers of Ag'IPV conjugate on the specimens (3). Extensive coating with serum protein obtained by storing the coated samples in fetal calf serum, which mimics in vitro the extracellular matrix (ECM) layers found in the in vivo conditions, did not hinder the ability of the covalently-tethered IPV derivative to bind the antibody and demonstrated that the Ag'-IPV coating remained stable 

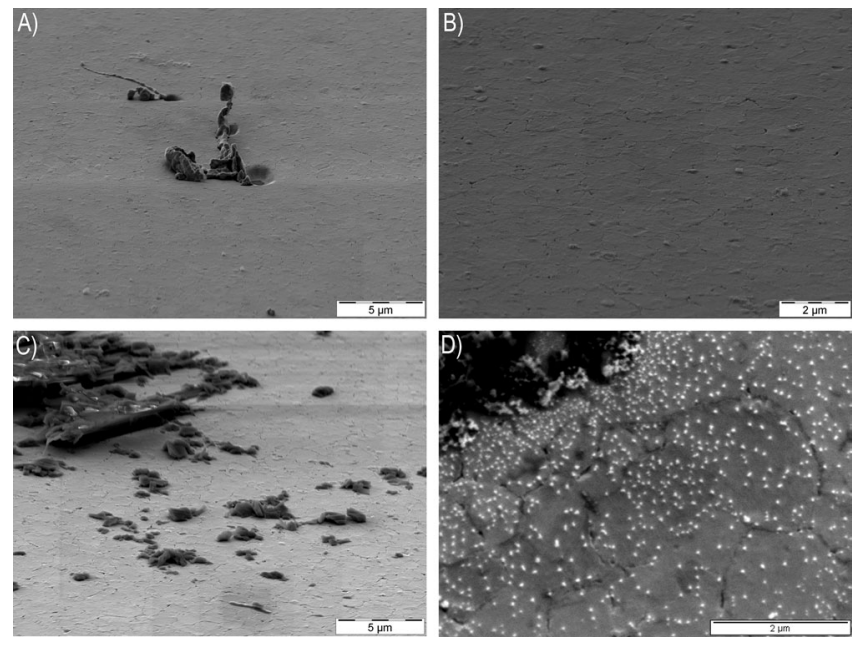

Figure 3. Scanning electron microscopy images at different positions and magnifications. A) and B) Coated Au(111)-SBri-Ag-IPV surface 2. C) and D) Coated Au(111)-SBri-Ag-Ag-[IPV-Ag] surface 3.

\begin{tabular}{|ll|}
\hline Table 1. Contact angle data for surfaces $\mathbf{1 - 3 .}$ & \\
\hline Surface & ${\left.\text { Angle [ }{ }^{\circ}\right]^{[\mathrm{a}}}^{\mathbf{3}}$ \\
\hline 1: $\mathrm{Au}(111)$ & $48.45 \pm 4.9$ \\
2: $\mathrm{Au}(111)-S B r i-A g-I P V$ & $34.15 \pm 4.1$ \\
3: Au(111)-SBri-Ag-[IPV-Ag] & $44.93 \pm 3.7$ \\
\hline [a] Data represent the mean of $n=3$. & \\
\hline
\end{tabular}

silver ions from both coated surfaces $\mathbf{2}$ and $\mathbf{3}$ into phosphatebuffered saline (PBS) solution at room temperature over 30 days, measured by inductively coupled plasma-optical emission spectroscopy (ICP-OES), is depicted in Figure $4 \mathrm{~A}$. The results indicated that coated specimen 3 released significantly more silver than specimen $\mathbf{2}$ throughout the entire incubation period. After $6 \mathrm{~h}$, approximately $1 \mathrm{ppm}\left(\mu \mathrm{g} \mathrm{m}^{-1}\right)$ was released into the PBS solution, followed by a plateau reached at day 4 with $2.29 \mu \mathrm{g} \mathrm{mL}^{-1}$ of silver ions. As the first $6 \mathrm{~h}$ after device implantation have been reported to be critical in reducing initial bacterial adhesion, ${ }^{[60]}$ this initial high release of silver ions from over a period of 1 month (Supporting Information). To confirm the previous results, scanning electron microscopy (SEM) images were taken on the coated gold surfaces (Figure 3 ). Results from the coated surfaces (2) showed a homogenous coating containing few nanoparticles (Figure $3 \mathrm{~A}$ and $\mathrm{B}$ ). The coating thickness was estimated to be about $1 \mu \mathrm{m}$ (Figure $3 \mathrm{~B}$ ). Surface 3 showed more microparticles or aggregates of IPV molecules (Figure 3C) embedded in a diffuse and thinner nanolayer of silver-containing nanoparticles (Figure 3D). The aggregate formation was concentration-dependent and confirmed the results obtained with immunodectection of IPV with a maximal aggregate size of $2 \mu \mathrm{m}$ confirmed by EDS analysis (Supporting Information).

Wettability seems to play a dominant role for adhesion of bacteria and cells ${ }^{[52]}$ onto a substrate, especially in the initial phase of cell-material interaction. ${ }^{[33,54]}$ Wettable (hydrophilic) surfaces are required for many biomaterials, as hydrophobic surfaces are considered to be more protein-adsorbent than hydrophilic surfaces. ${ }^{[55-57]}$ Cells have been observed to adhere, spread, and grow more on moderately wettable surfaces with water contact angles of $50-70^{\circ} .{ }^{[58,59]}$ A surface could be considered hydrophilic when the angle $\theta$ is smaller than $90^{\circ}$. Contact angle data is shown in Table 1 for water sessile drops on uncoated $\mathrm{Au}(111)$ surfaces $\mathbf{1}$ and coated surfaces $\mathbf{2}$ and $\mathbf{3}$. While the intermediately coated surfaces (2) are more hydrophilic than the uncoated surfaces (1), the final coated surfaces (3) have a contact angle close to $50^{\circ}$.

As coordinative bonds between silver ions and IPV molecules are used to create this antimicrobial coating, release kinetics of the two antimicrobial drugs, IPV and silver, were studied over time. The release of
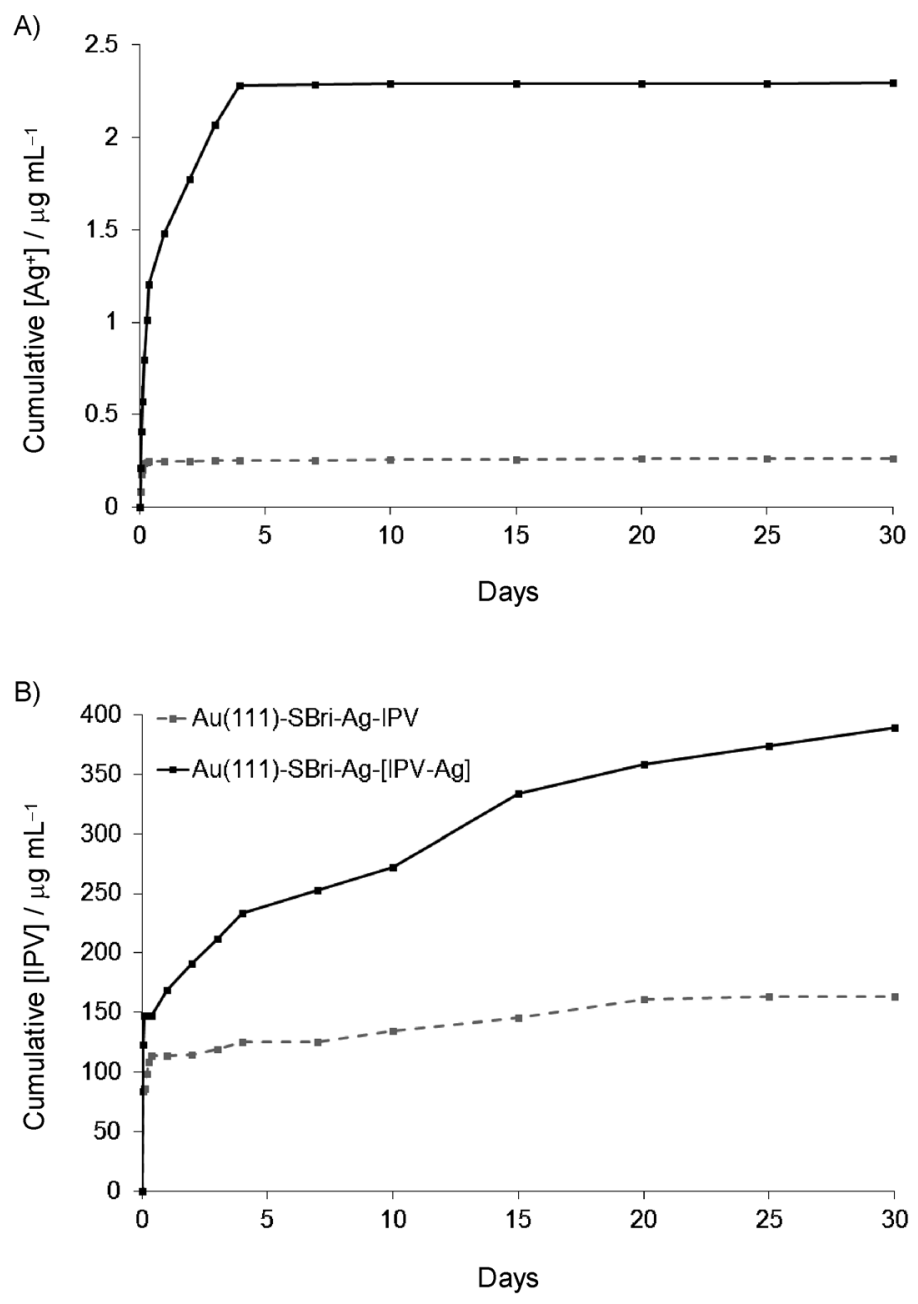

Figure 4. The curve of both drugs release from coated Au(111)-SBri-Ag-IPV surfaces 2 and coated Au(111)-SBri-Ag-[IPV-Ag] surfaces 3 immersed in PBS over a period of 30 days. A) Silver release profile. B) IPV release profile. 
our coatings is favorable to fight bacterial adhesion. Compared to our Ag'-IPV conjugate coated surfaces 3, we noticed that the intermediately coated surfaces (2) only released silver ions for $2 \mathrm{~h}$, and only a low concentration $\left(0.25 \mu \mathrm{g} \mathrm{mL}^{-1}\right)$ could be measured after seven days. These data confirmed our hypothesis of the Ag'-IPV multilayer formation upon coordination to silver, and hence stronger silver release, in coatings of type 3 . Such multiple layers may form, for example, via back-to-back dimer formation of the VAN moiety of IPV. Indeed, it was shown that VAN is highly active in its dimeric form. ${ }^{[18,61]}$ We propose that such interactions take place upon aggregate formation in coatings of $\mathbf{3}$ as well, mediated by silver ion coordination.

The release solutions from both coated specimens $\mathbf{2}$ and $\mathbf{3}$ were measured by UV-Vis spectroscopy at a wavelength of $280 \mathrm{~nm}$ for each immersion time in PBS in order to detect released IPV. The release profile of IPV is depicted in Figure 4B. More IPV molecules were released into the PBS buffer from coated specimen $\mathbf{3}$ than from specimen $\mathbf{2}$ throughout the whole incubation period, which indicated that more IPV was deposited when silver(I) ions were present in the final coating solution. This is in accordance with the results obtained by immunodectection.

We observed that $40 \%$ of IPV was released from coated surfaces 3 during the first $9 \mathrm{~h}$ and $30 \%$ during the following 5 days, with released concentrations values higher than the minimal bactericidal concentration $(\mathrm{MBC})$ value. We noticed that the release profile of our IPV drug from IPV-Ag conjugate surfaces $\mathbf{3}$ was similar to another study ${ }^{[62]}$ in which hydroxyapatite pores coated on TiAIV were filled with VAN-chitosan composite, providing prophylaxis and therapy for osteomyelitis. This high release of IPV $\left(147.4 \mu \mathrm{g} \mathrm{mL}^{-1}\right)$ during the first hours would be advantageous in combination with silver(l) ions to fight bacterial adhesion at the site of implantation. We also observed a slower release of the remaining 30\% IPV $\left(116.8 \mu \mathrm{g} \mathrm{mL}^{-1}\right)$ during the next 25 days, indicating that our newly coated Ag'-IPV conjugate surface (3) may also act as a postoperative treatment against infections and will not favor bacterial resistance. The IPV release profile is in accordance with the ideal antibiotic release profile, with a burst release (high release rate) for fighting bacteria during surgical implantation, followed by sustained released with an efficacious dose to hinder latent infections. ${ }^{[63]}$

\section{Bacterial evaluation}

The minimal inhibitory concentration (MIC) and the MBC values have been established to determine the susceptibility of Staphylococcus epidermidis and S. aureus to the new IPV compared to VAN. The MIC is defined as the lowest concentration of an antibiotic that will inhibit the (in vitro) growth of an infectious organism. The MBC is the first dilution at which no growth is observed and is defined as the lowest concentration of an antimicrobial agent needed to kill $99.9 \%$ of the initial organism inoculum. VAN inhibited an S.epidermidis strain at $0.63 \mu \mathrm{g} \mathrm{mL}^{-1}$, while S. aureus was more resistant. It was found that the IPV derivative retained activity against VAN-susceptible
Gram-positive bacteria and showed similar activity to VAN against both strains, with MIC values of $2.5 \mu \mathrm{g} \mathrm{mL}^{-1}$ and $5 \mu \mathrm{g} \mathrm{mL}^{-1}$ for S. epidermidis and S. aureus, respectively. The MBC values for both VAN and its derivative, IPV, remained quasi-identical. The antimicrobial susceptibility of a drug is evaluated by the MIC/MBC ratio. A compound is generally considered to be bactericidal if the ratio of MIC to $M B C$ is $\leq 4$. Both Staphylococci strains were thus sensitive to VAN and IPV (Table 2). Comparing the MBC/MIC ratio for both VAN and its derivative IPV, we concluded that our new IPV was active and bactericidal against both Staphylococci strains and that modification of the $\mathrm{C}$ terminus of VAN did not affect the bacterial activity.

\begin{tabular}{|c|c|c|c|c|c|c|}
\hline \multirow[t]{2}{*}{ Compd } & \multicolumn{2}{|c|}{$\mathrm{MIC}\left[\mu \mathrm{gmL}^{-1}\right]$} & \multicolumn{2}{|c|}{$\mathrm{MBC}\left[\mu \mathrm{gL}^{-1}\right]$} & \multicolumn{2}{|c|}{$\mathrm{MBC} / \mathrm{MIC}$} \\
\hline & SE & SA & SE & SA & SE & SA \\
\hline VAN & 0.63 & 2.50 & 1.25 & 5.00 & 1.98 & 2.00 \\
\hline IPV & 2.50 & 5.00 & 2.50 & 5.00 & 2.00 & 2.00 \\
\hline
\end{tabular}

[a] MIC and MBC values were determined by macrobroth dilution according to NCCLS guidelines. Data represent the mean of $n=3$.

The antimicrobial activity of our new surfaces, modified by silver-IPV conjugate, was also investigated via Kirby-Bauer tests. ${ }^{[64]}$ In our case, permissive agar plates were used in which the inhibition of bacterial growth around the coated gold surfaces was measured. The size of the inhibition zone is usually related to the level of antimicrobial activity present in the sample or product. A larger zone of inhibition usually means that the antimicrobial compound is more potent. Different concentrations of silver-IPV conjugate compound tested positively against both Gram-positive (S. aureus and S. epidermidis) and Gram-negative ( $E$. coll) bacteria, with inhibition zones ranging from 10 to $16 \mathrm{~mm}$. The antimicrobial effect was concentration- and bacterial inoculum-dependent (Supporting Information). Moreover, the Gram-positive S. aureus strain, which is primarily responsible for implant-related infections, was susceptible against both of our modified surfaces (Figure 5).

Indeed, coated surfaces $\mathbf{2}$ and $\mathbf{3}$ led to a reduction in S. aureus growth with maximal inhibition zone diameters of $13 \mathrm{~mm}$ and $20 \mathrm{~mm}$, respectively, at $10^{4} \mathrm{CFU} \mathrm{mL}^{-1}$. At a high bacterial concentration $\left(10^{6} \mathrm{CFU} \mathrm{mL}^{-1}\right)$, maximal inhibition zones of $10 \mathrm{~mm}$ and $18 \mathrm{~mm}$ were observed, respectively. Our data showed that, when silver(l) ions were used in combination with IPV in the final layer, the antimicrobial activity of our developed coating (3) increased significantly. The inhibition zones reached up to $20 \mathrm{~cm}$ in diameter, which is a characteristic of very efficient antimicrobial agents and may be attributed to synergistic effects of the two compounds.

Combining both silver(I) ion and IPV release profiles with these data, we assumed that the multilayered Ag'-IPV conju- 


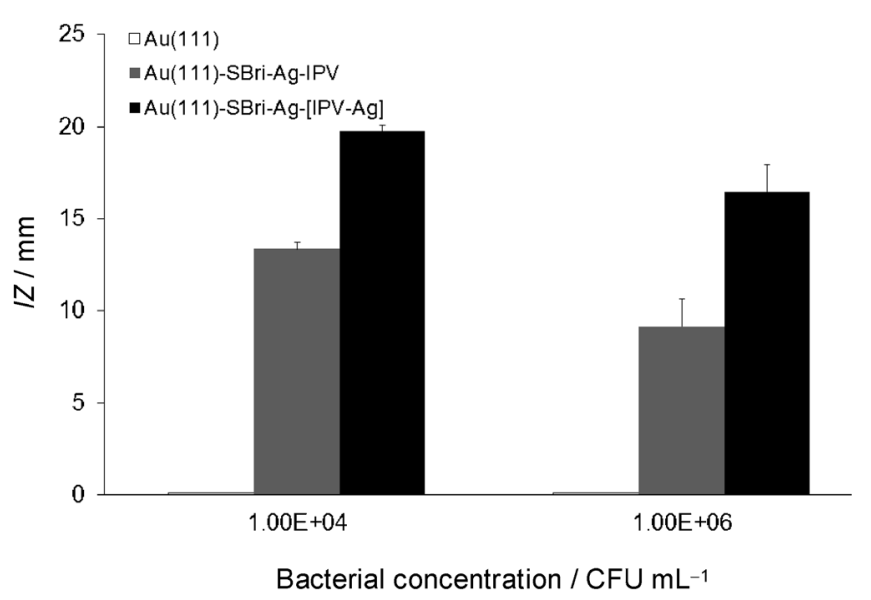

Figure 5. Agar inhibition assay (Kirby-Bauer test) with S. aureus 113 at $10^{4}$ and $10^{6} \mathrm{CFU} \mathrm{mL}{ }^{-1}$. Effect of uncoated $\mathrm{Au}(111)$ surfaces 1 , coated $\mathrm{Au}(111)$ SBri-Ag-IPV surfaces 2, and coated Au(111)-SBri-Ag-[IPV-Ag] surfaces 3.

gates would create an efficient antimicrobial coating that would immediately release $\mathrm{Ag}^{\prime}$ ions and antibiotic derivatives at the site of implantation. This would be advantageous, as high local doses could be administered without exceeding the systemic toxicity level of the drugs. ${ }^{[65,66]}$

\section{Cytotoxicity and cell adhesion evaluation}

Cytotoxicity testing of implantable biomaterials is mandatory in safety assessment. Mouse fibroblast cells were thus used as a cell model to investigate the effects of our new coated surface variations on soft tissue response, as fibroblasts are strongly involved in the wound healing process. ${ }^{[67]}$ MTT activity assays using fibroblast-like cells to study cell proliferation and by extension, cell cytoxicity, were performed, followed by cell morphology studies. Comparison of the proliferation activity from coated specimens versus untreated controls was spectrophotometrically quantified. A decrease in MTT reduction reflects the loss of cell viability in cells that are undergoing apoptosis. As a control, cells were grown on plastic and uncoated $\mathrm{Au}(111)$ surfaces (1), and each assay was carried out in triplicate for statistical evaluation (Figure 6)

Cells grew well on uncoated surfaces 1 and coated surfaces 2 and 3, showing an increase in MTT activity with incubation time, as shown in Figure 7. Fibroblast cell growth continued to increase after 3 days in culture, indicating that proliferation proceeded for all specimens. Comparing the cellular response to uncoated surface 1 , a slower cell response was observed for both coated surfaces 2 and 3. Both coatings 2 and $\mathbf{3}$ performed similarly in this biocompatibility test, reaching half of the optical density after $48 \mathrm{~h}$ as compared to coating 1 , and $35 \%$ after $72 \mathrm{~h}$. Although slower proliferation was observed, we concluded from the above results that our new bactericidal coated surfaces, $\mathbf{2}$ and 3, enhanced bioactivity and were promising for further in vitro experiments.

The long-term success of an implant, such as a dental implant, strongly depends on good adhesion of the surrounding tissue to the biomaterial. In culture, most cells adhere to their

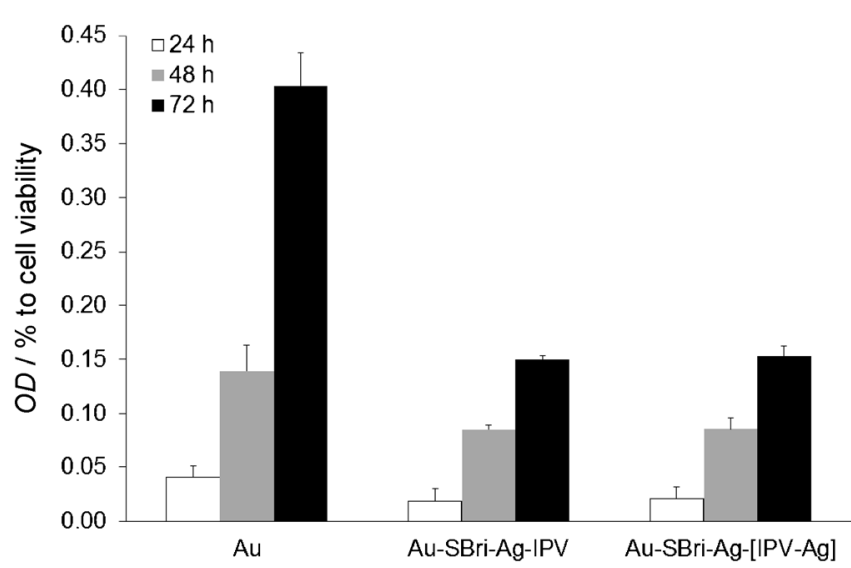

Figure 6. MTT assay of uncoated Au(111) surfaces 1, coated Au(111)-SBri-AgIPV surfaces 2, and coated Au(111)-SBri-Ag-[IPV-Ag] surfaces 3 . Cell viability was assessed after cells were cultures for $24 \mathrm{~h}, 48 \mathrm{~h}$, and $72 \mathrm{~h}$.
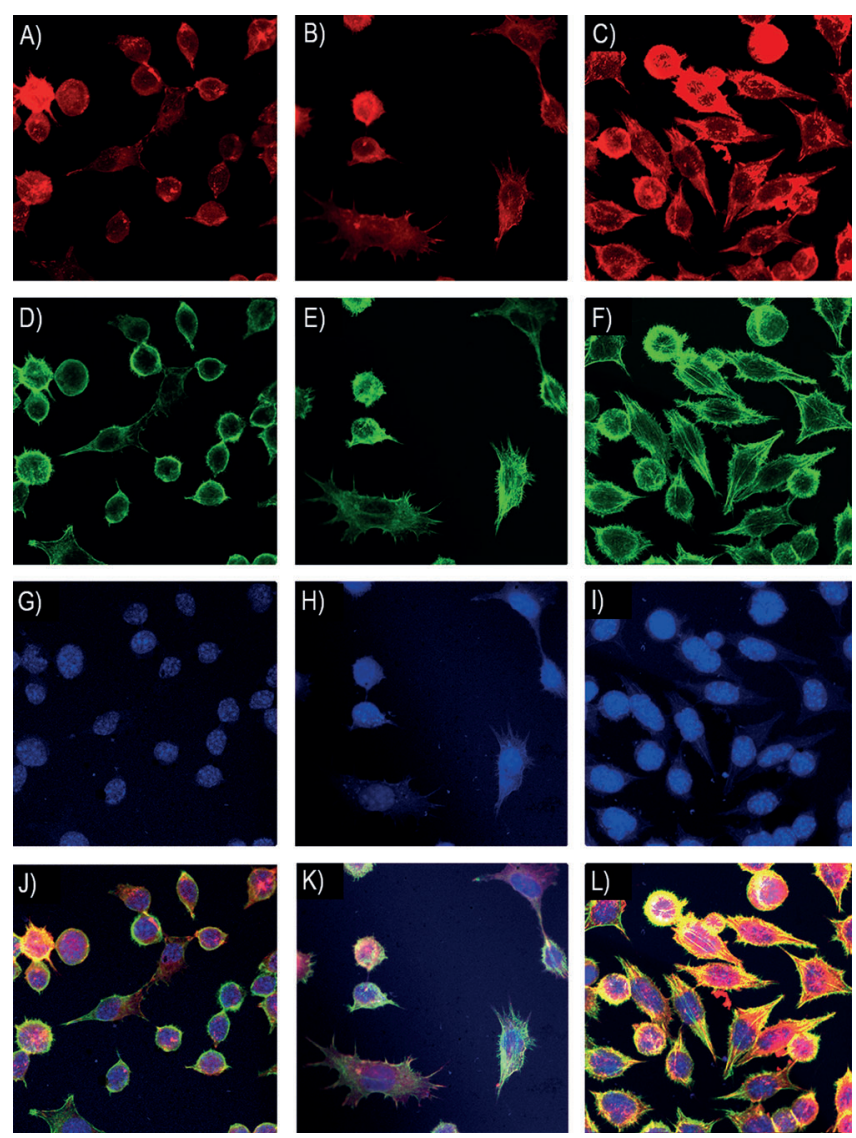

Figure 7. Indirect immunofluorescence of focal adhesion contact sites in murine fibroblast cells as revealed by vinculin staining in red $(A, B, C)$, actin staining in green $(D, E, F)$, nucleus staining in blue $(G, H, I)$ and the merged images $(J, K, L)$. Note that both proteins are co-distributed in focal adhesion. Effect of uncoated surfaces 1 (A, D, G, J), coated Au(111)-SBri-Ag-IPV surfaces $2(B, E, H, K)$ and coated $A u(111)-S B r i-A g-[I P V-A g]$ surfaces $3(C, F, I, L)$.

underlying substrate by means of focal adhesion contacts (FACs), which are restricted areas of extremely close contact between the basal cell membrane and the substratum. ${ }^{[68-70]}$ Focal contacts can be identified by the presence of actin bind- 
ing to the protein vinculin. They provide sites of mechanical attachment to the ECM and are proteins at which adhesion-associated signal transduction is initiated. The adhesion phase involves various biological molecules like ECM proteins, cell membrane proteins, and cytoskeletal proteins, which interact together to induce signal transduction, promoting the action of transcription factors and consequently regulating gene expression. ${ }^{[71]}$ Cell spreading and adhesion are phenomena involving complex cytoskeletal reorganization. However, fibroblast cell types have focal adhesions that exhibit dash and dot adhesions. ${ }^{[72]}$ The presence of the larger, mature, dash adhesion around the periphery of fibroblast, as well as along the stress fibers, can be used as an indicator of cytocompatibility.

We first visualized the intracellular actin molecules in FAC areas on uncoated $\mathrm{Au}(111)$ surfaces 1 and coated surfaces 2 and $\mathbf{3}$ using the indirect immunofluorescence labeling method. To quantify fibroblast adhesion on uncoated surface 1 and coated surfaces $\mathbf{2}$ and $\mathbf{3}$, the focal adhesion protein vinculin was immunolabeled in red (Figure $7 \mathrm{~A}-\mathrm{C}$ ), whereas the actin protein was immunolabeled in green (Figure 7D-F). Nuclei were visualized in blue by using a DAPI stain (Figure 7G-I). A control was designed by omitting the primary antibody for all specimens. We observed that all actin distributed around the nucleus creates fibers and connections with other cells. Vinculin proteins were observed around the nucleus and were co-localized with the actin protein. These observations indicate that cells attach to all uncoated surfaces 1 and coated surfaces 2 and $\mathbf{3}$ and develop their cytoskeleton as a sign of good proliferation and adhesion.

The morphology of the fibroblast-like cells, incubated on uncoated surfaces $\mathbf{1}$ and coated surfaces $\mathbf{2}$ and $\mathbf{3}$ for 3 days, is shown on Figure 8, revealing spreading filopodia and an obvious nucleus on the cells. This indicated that the coated specimens $\mathbf{2}$ and $\mathbf{3}$ provide a good environment for fibroblast cells, consistent with the results of MTT activity assays.

We demonstrated in this study that our IPV-Ag conjugate coatings inhibit both Gram-positive and Gram-negative bacteria and could be efficient against adherent bacteria as well as non-adherent bacteria, as both drugs are released. Indeed, this coordination-type binding renders the antibiotic and the silver available for acting against all different classes of organisms and not only against a specific class of bacteria, as shown in other studies. $^{[4-7]}$
These studies regarding covalently bound vancomycin to titanium without any release of the drug show only an effect on Gram-positive bacteria adherence, with a minimal effect on Gram-negative bacteria adherence and no effect on non-adherent bacteria. ${ }^{[4-7]}$ Moreover, we show in this study that both drugs, the IPV molecule and silver(I) ions, have a synergic effect on killing bacteria and will thus be an option for both Gram-positive and Gram-negative infection treatments. Indeed, it has been shown that a synergetic effect of AgNPs, combined with sulfonamide and glycopeptide drugs, increased the susceptibility of different bacteria. ${ }^{[15-17,73-75]}$ For example, Ramirez et al. ${ }^{[17]}$ demonstrated that the increase in reactive oxygen species production and membrane permeability caused by $\mathrm{Ag}^{+}$, triggering the bacterial cellular network, enhances the activity of their tested antibiotic arsenal. We also propose that our IPV-Ag conjugate coating system would become a promising alternative to the commonly gentamicin-impregnated bone cements, based on non-biodegradable polymer polymethylmethacrylate (PMMA). Indeed, some studies on gentamicin-impregnated PMMA cement have shown bacterial adhesion and growth on antibiotic-loaded cement, as well as development of bacterial resistance strains, despite the release of antibiotics. ${ }^{[76-79]}$

\section{Conclusions}

Vancomycin was derivatized with a pyridinyl group at its $C$ terminus without loss of stability and antimicrobial activity. Indeed, the IPV derivative remained bactericidal against both S. aureus and S. epidermidis strains. IPV was deposited in a final layer of a supramolecular surface coating, either in pure form or as a silver complex. In the latter case, a higher IPV coating was detected on the gold surfaces than on the control surfaces, and the homogenous and nanostructured, multilayered Ag'-IPV conjugate tested positively against both studied Staphylococci strains. Release profiles of both the silver(I) ions and the IPV derivative showed promising results for the immediate availability of these two drugs, which can prevent bacterial adhesion, at the site of implantation. This new antimicrobial Ag'-IPV conjugate coating shows good and encouraging biocompatibility for soft tissue integration for further in vivo studies.
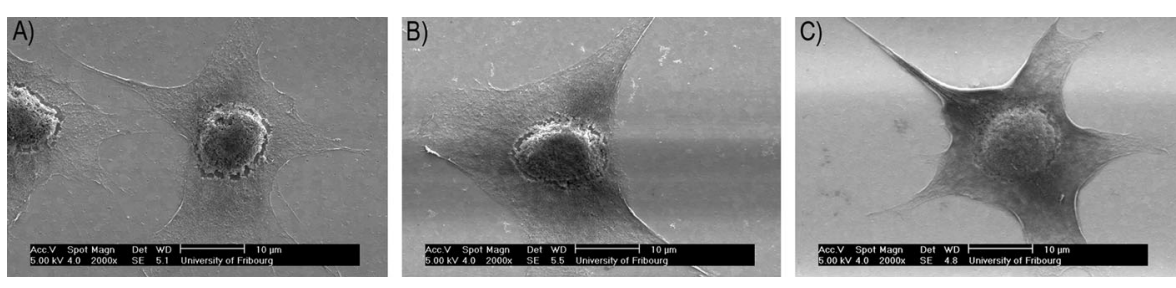

Figure 8. Effect of Ag-IPV conjugate-coated surfaces on fibroblast cells. A) uncoated surfaces 1. B) Coated Au(111)SBri-Ag-IPV surfaces 2. C) Coated Au(111)-SBri-Ag-[IPV-Ag] surfaces 3. Cell proliferation was assessed at day 3. Cells were fixed onto surfaces, dehydrated, thinly sputter-coated with gold, and examined using a scanning electron microscope.

\section{Experimental Section}

\section{Material Preparation}

General: All chemicals and solvents were purchased in the highest available quality. Coupling agent $\quad 0$-(7-azabenzotriazol-1-yl)$N, N, N^{\prime}, N^{\prime}$-tetramethyluronium hexafluorophosphate (HATU), diisopropylethylamine (DIEA), 4-aminopyridine, and thiazolyl blue tetrazolium (MTT reagent) were purchased from Sigma-Aldrich. Monoproctected Fmoc-8-amino-3,6-dioxaoc- 
tanoic acid (Fmoc-AEEA) was purchased from Peptides International, rabbit anti-VAN IgG antibody was obtained from Acris, and human anti-vinculin (hVIN-1) and anti-mouse IgG Alexa Fluor 546 antibodies were purchased from Lubioscience. Commercial vancomycin Vancocin ${ }^{\circledR}$ was provided by Teva Pharma. ESI-MS spectra were recorded with a BRUKER FTMS 4.7T BioAPEX ॥ (CombiSource). ${ }^{1} \mathrm{H}$ NMR analyses were performed on a Bruker 400 Utrashield spectrometer. Differential scanning calorimetry (DSC) measurements were obtained from a Mettler DSC-30 instrument. UV/vis properties were analyzed on a PerkinElmer Lambda $40 \mathrm{UV} / \mathrm{vis}$ spectrometer. Measurements were collected in liquid solution.

IPV derivative synthesis using liquid-phase peptide synthesis: Fmoc-AEEA $(617 \mathrm{mg}, 1.6 \mathrm{mmol}$ ) was added to a solution of 4-aminopyridine $(94 \mathrm{mg}, 1 \mathrm{mmol})$ in DMF $(10 \mathrm{~mL})$. The mixture was cooled to $2{ }^{\circ} \mathrm{C}$, and HATU (608 mg, $1.6 \mathrm{mmol}$ ) was added, followed by DIEA $(0.56 \mathrm{~mL}, 3.2 \mathrm{mmol})$. The solution was stirred for $1 \mathrm{~h}$ at $2{ }^{\circ} \mathrm{C}$ and then allowed to warm to RT and stirred overnight, followed by Fmoc deprotection with $20 \%$ piperidine in DMF at RT for $5 \mathrm{~h}$. Reaction completion was confirmed by thin-layer chromatography (TLC). The reaction was concentrated in vacuo to give the crude product $(958 \mathrm{mg})$, which was then dissolved in water $(20 \mathrm{~mL})$. The aqueous phase was washed with $\mathrm{CH}_{2} \mathrm{Cl}_{2}(2 \times 20 \mathrm{~mL})$. The water solution was purified by preparative reversed-phase HPLC (linear gradient from $5 \%$ to $40 \%$ using $0.1 \%$ trifluoroacetic acid (TFA) in $\mathrm{CH}_{3} \mathrm{CN}$ for $30 \mathrm{~min}$ ) and lyophilized to afford AEEA linker $3(211 \mathrm{mg}, 0.88 \mathrm{mmol}, 88 \%)$ : ${ }^{1} \mathrm{H}$ NMR $\left(300 \mathrm{MHz}, \mathrm{CDCl}_{3}\right): \delta=$ $8.45\left(\mathrm{~d}, 2 \mathrm{H}, \mathrm{CH}_{\mathrm{ar}}\right), 8.17\left(\mathrm{~d}, 2 \mathrm{H}, \mathrm{CH}_{\mathrm{ar}}\right), 4.15\left(\mathrm{~s}, 2 \mathrm{H}, \mathrm{COCH}_{2} \mathrm{O}\right), 3.18(\mathrm{~m}$, $\left.6 \mathrm{H}, \mathrm{OCH}_{2} \mathrm{CH}_{2}\right), 1.83 \mathrm{ppm}\left(\mathrm{s}, 2 \mathrm{H}, \mathrm{CH}_{2} \mathrm{CH}_{2} \mathrm{NH}\right)$; ESI-MS (293 K): $\mathrm{m} / \mathrm{z}=$ $240.1[\mathrm{M}+\mathrm{H}]^{+}$.

VAN (1449 mg, $1 \mathrm{mmol}$ ) was then coupled to linker 3 (211 mg, $0.88 \mathrm{mmol}$ ) using the same procedure as described above. Removal of the solvent afforded the crude product, which was purified by semi-preparative reversed-phase HPLC (linear gradient from $5 \%$ to $40 \%$ using $0.1 \%$ TFA in $\mathrm{CH}_{3} \mathrm{CN}$ for $30 \mathrm{~min}$ ) and lyophilized to afford IPV (750 mg, $0.45 \mathrm{mmol}, 51 \%)$ : ${ }^{1} \mathrm{H}$ NMR (400 MHz, $\mathrm{D}_{2} \mathrm{O}$ ): same resonance as VAN, with $\delta=8.49\left(\mathrm{~d}, 2 \mathrm{H}, J=6.2 \mathrm{~Hz}, \mathrm{CH}_{\mathrm{ar}}\right), 8.01$ $\left(\mathrm{d}, 2 \mathrm{H}, J=6.9 \mathrm{~Hz}, \mathrm{CH}_{\mathrm{ar}}\right), 4.30\left(\mathrm{~s}, 2 \mathrm{H}, \mathrm{COCH}_{2} \mathrm{O}\right), 3.00(\mathrm{~s}, 6 \mathrm{H}$, $\left.\mathrm{OCH}_{2} \mathrm{CH}_{2}\right), 2.58 \mathrm{ppm}$ (s, $\left.2 \mathrm{H}_{1} \mathrm{CH}_{2} \mathrm{CH}_{2} \mathrm{NH}\right)$; ESI-MS (293 K): $\mathrm{m} / \mathrm{z}=$ $1671.55[\mathrm{M}+\mathrm{H}]^{+}$.

Coating of $\mathrm{Au}(\mathbf{1 1 1})$ : Flame-annealed gold monolayer plates were pre-treated with disulfide solution $[5 \mathrm{~mm}$ bis 2-((4-pyridinylcarbonyl)oxy)ethyl disulfide dissolved in $\mathrm{CH}_{2} \mathrm{Cl}_{2} / \mathrm{EtOH}$ (1:1)]. After 7 days of incubation, the gold plates were washed with $\mathrm{EtOH}$ and immediately placed in a $5 \mathrm{~mm}$ silver solution for 7 days in the dark, followed by washing with $\mathrm{EtOH}$. The plates were then immersed in a $2 \mathrm{~mm} \mathrm{IPV} \mathrm{solution} \mathrm{for} 1$ month. A $2 \mathrm{~mm}$ silver solution was then directly added, and the plates were incubated for 1 day at RT. Finally, all of the plates were washed with $\mathrm{EtOH}$ and dried in the dark under vacuum over $\mathrm{P}_{2} \mathrm{O}_{5}$. The prepared samples were kept in the dark in a closed, clean container.

Anti-vancomycin immunodetection: The test substrates were washed once with phosphate-buffered saline (PBS) and incubated in a blocking solution containing $5 \%$ goat serum and $1 \%$ FCS in PBS for 30 min at RT. After rinsing the substrates twice with PBS, primary antibody rabbit anti-VAN IgG (1:150) was added in a 1.5\% milk solution for $2 \mathrm{~h}$ at RT. Substrates were rinsed twice with PBS prior to addition of the secondary goat anti-rabbit Alexa Fluor 514 antibody (1:400) in a $1.5 \%$ milk solution for $2 \mathrm{~h}$ at RT. After a final rinse, the substrates were mounting onto a glass slide before visualization under a confocal microscope.
Scanning electron microcopy: SEM was used to examine the surface topography on the modified gold plates before incubation with fibroblasts (FEI XL 30 Sirion FEG).

Surface wettability: To characterize surface wettability, contact angle analysis was performed on all surface modifications. The sessile water drop method was used for contact angle measurement. For every surface modification, three measurements were made at RT to provide adequate replications for statistical analysis. Pictures were treated using ImageJ with the "Contact Angle" plug-in.

Drug release: Absorption of silver(I) ion measurements were determined using an inductively coupled plasma-optical emission spectroscopy (ICP-OES) Perking Elmer Optima 7000DV spectrometer. Diluted $\mathrm{HNO}_{3}(2.2 \mathrm{M})$ was used to keep the silver ions in solution. Absorption of IPV measurements were determined using a UV/Vis Perking Elmer Lambda 40 spectrometer.

\section{Bacterial evaluation}

Bacterial strains and growth conditions: S. aureus $113^{[80]}$ and S. epidermidis $1457^{[81]}$ were freshly grown in tryptic soy broth (TSB) for $7 \mathrm{~h}$ at $37^{\circ} \mathrm{C}$ without shaking. A 1:100 dilution was used to inoculate the overnight culture. Bacterial numbers were estimated by determining the optical density at $600 \mathrm{~nm}$ and assessed by plating serial dilutions on Mueller Hinton agar (MHA). In the agar experiments, this overnight culture was directly diluted to the desired inoculum.

MIC/MBC assay: MIC and MBC values were determined according to the macrodilution method of the Clinical and Laboratory Standards Institute (CLSI).

Agar inhibition assays (Kirby-Bauer test): MHA was melted and then cooled to approximately $50^{\circ} \mathrm{C}$. S. aureus 113 bacteria were diluted to $1 \times 10^{4} \mathrm{CFU} \mathrm{mL}^{-1}$ and at $1 \times 10^{6} \mathrm{CFU} \mathrm{mL}^{-1}$ in the agar. Substrates were completely covered with agar and incubated for $18 \mathrm{~h}$ at $37^{\circ} \mathrm{C}$. The diameters of the inhibition zones around the substrates were measured.

\section{Cell adhesion evaluation}

Cell culture: L-929 mouse fibroblasts (ATTC: CCL-1) were used as a cell model to investigate the effect of surface and material variation on soft-tissue response. The fibroblast cultures were maintained in RPMI 1640 (Invitrogen) supplemented with 10\% fetal bovine serum, $1 \%$ penicillin-Streptomycin, $1 \mathrm{X}$ non-essential amino acids and $1 \mathrm{~mm}$ sodium pyruvate at $37^{\circ} \mathrm{C}$ in humidified air and $5 \%$ $\mathrm{CO}_{2}$. Cultures were subdivided by trypsinisation using trypsin-EDTA solution. The modified substrates were placed in standard 24-well tissue culture plates before seeding the cells at an inoculum of 20000 cells per well. As a control substrate for cell attachment and growth, fibroblasts were plated directly onto tissue culture polystyrene plastic. Cells were incubated for $24 \mathrm{~h}, 48 \mathrm{~h}$ and $72 \mathrm{~h}$ at $37^{\circ} \mathrm{C}$ in humidified air and $5 \% \mathrm{CO}_{2}$. All subsequent experiments were performed in triplicate and were repeated twice.

Cell morphology (scanning electron microscopy): The test substrates were pre-incubated in RPMI medium supplemented with $10 \%$ FCS for $18 \mathrm{~h}$ at $37^{\circ} \mathrm{C}$, then washed with PBS and placed in new 24-well plates. Cells were seeded at a density of $2 \times 10^{4}$ cells $/ 1.9 \mathrm{~cm}^{2}$ onto the test substrates. At $72 \mathrm{~h}$, fibroblasts were rinsed with PBS to remove non-adherent cells and then fixed with $4 \%$ paraformaldehyde for $10 \mathrm{~min}$ at RT. After a final rinse with PBS and water, cells were dehydrated through a graded series of $\mathrm{EtOH}(30 \%, 50 \%$, 
$70 \%, 90 \%$, and $100 \%)$. After air-drying, substrates were thinly sputter-coated with gold. Fibroblasts on gold served as controls.

Focal adhesion contact sites (immunochemistry): To visualize the intracellular actin and vinculin in FACs areas, immunochemistry was performed. The test substrates were pre-incubated in RPMI medium supplemented with $10 \%$ FCS for $18 \mathrm{~h}$ at $37^{\circ} \mathrm{C}$, then washed with PBS and placed in new 24-wells plate. Cells were seeding at the right density onto the tests substrates. At $72 \mathrm{~h}$, fibroblasts were rinsed with PBS to remove the non-adherent cells and then fixed with $4 \%$ paraformaldehyde and $0.2 \%$ Triton X100 solution for $8 \mathrm{~min}$ at RT. The substrates were rinsed twice with PBS before storage at $4^{\circ}$ in PBS solution. The substrates were incubated in a blocking solution containing $5 \%$ goat serum and $1 \%$ FCS in PBS for unspecific binding for $30 \mathrm{~min}$ at RT, followed by two washes with PBS. The primary antibody, human anti-vinculin (hVIN$1 ; 1: 300$ ) was added in a $1.5 \%$ milk solution and incubated for $2 \mathrm{~h}$ at RT. After three rinses with PBS, the secondary anti-mouse IgG Alexa Fluor 546 antibody (1:400) and DAPI stain (1:1000) were added in a $1.5 \%$ milk solution for $2 \mathrm{~h}$ at RT. Following three rinses after each substrate with PBS, Alexa Fluor 488 phallaoidin (1:40) was added and incubated $20 \mathrm{~min}$ at RT, followed by a final rinse before analysis by confocal microscopy.

Cytotoxicity evaluation: A quantitative colorimetric MTT test was performed after $24 \mathrm{~h}, 48 \mathrm{~h}$, and $72 \mathrm{~h}$ culture to characterize cellular metabolism. The test substrates were pre-incubated in RPMI medium supplemented with $10 \%$ FCS for $18 \mathrm{~h}$ at $37^{\circ} \mathrm{C}$, then washed with PBS and placed in new 24-well plates. Cells were seeded at a density of $2 \times 10^{4}$ cells $/ 1.9 \mathrm{~cm}^{2}$ onto the test substrates. At $24 \mathrm{~h}, 48 \mathrm{~h}$, and $72 \mathrm{~h}$, the test substrates were placed in new wells, and $500 \mu \mathrm{L}$ of fresh medium was added, followed by the addition of $50 \mu \mathrm{L}$ of MTT solution [5 mg mL $\mathrm{m}^{-1}$-(4,5-dimethylthiazol-2yl)-2,5-diphenyl-tetrazolium bromide in PBS] to each well. Cells were incubated at $37^{\circ} \mathrm{C}$ for $4 \mathrm{~h}$, then medium was removed from each well and stored at $4^{\circ} \mathrm{C}$ for hours. Dimethylsulfoxide (DMSO; $500 \mu \mathrm{L}$ ) was added to each well, followed by 30 min incubation at RT on a shaker. A $150 \mu \mathrm{L}$ aliquot of each solution was transferred to a 96-well plate. Optical density was measured at $540 \mathrm{~nm}$ with a Hidex Sense Beta Plus.

\section{Acknowledgements}

The authors thank the Swiss National Foundation, Fribourg Center for Nanomaterials (FriMat), Switzerland, and the University of Fribourg (Switzerland) for supporting this project. They also thank Prof. Dr. MD. Marco Celio (University of Fribourg) for providing fibroblast cells and Zarko Rajacic and Anne-Kathrin Woischnig (Infection Biology, Department of Biomedicine, University Hospital in Basel) for performing in vitro assays. Finally, a special thanks to Teva Pharma for providing the Vancocin ${ }^{\circledR}$ used in this study.

Keywords: gold surfaces · antimicrobial action - medical implants $\cdot$ silver $\cdot$ vancomycin

[1] J. W. Costerton, P. S. Stewart, E. P. Greenberg, Science 1999, 284, 1318 1322.

[2] P. Gilbert, J. Das, I. Foley, Adv. Dental Res. 1997, 11, 160-167.

[3] J. W. Costerton, P. S. Stewart, Sci. Am. 2001, 285, 74-81.

[4] B. Jose, V. Antoci, A. R. Zeiger, E. Wickstrom, N. J. Hickok, Chem. Biol. $2005,12,1041-1048$
[5] V. Antoci, S. B. King, B. Jose, J. Parvizi, A. R. Zeiger, E. Wickstrom, T. A Freeman, R. J. Composto, P. Ducheyne, I. M. Shapiro, N. J. Hickok, C. S. Adams, J. Orthop. Res. 2007, 25, 858-866.

[6] V. Antoci, C. S. Adams, J. Parvizi, H. M. Davidson, R. J. Composto, T. A. Freeman, E. Wickstrom, P. Ducheyne, D. Jungkind, I. M. Shapiro, N. J. Hickok, Biomaterials 2008, 29, 4684-4690.

[7] S. Stewart, S. Bar, J. Engiles, N. J. Hickok, I. M. Shapiro, D. W. Richardson, J. Parvizi, T. S. Schaer, J. Bone Jt. Surg. Am. Vol. 2012, 94, 1406-1415.

[8] J.-Y. Wach, S. Bonazzi, K. Gademann, Angew. Chem. 2008, 120, 7232 7235; Angew. Chem. Int. Ed. 2008, 47, 7123-7126.

[9] P. Vaudaux, P. Francois, B. Berger-Bächi, D. P. Lew, J. Antimicrob. Chemother. 2001, 47, 163-170.

[10] K. M. Fromm, Chimia 2013, 67, $851-854$.

[11] M. K. Rai, S. D. Deshmukh, A. P. Ingle, A. K. Grade, J. Appl. Microbiol. 2012, 112, $841-852$.

[12] B. P. Sekhon, J. Pharm. Educ. Res. 2010, 1, 1-20.

[13] K. Y. Yoon, J. H. Byeon, J. H. Park, J. Hwang, Sci. Total Environ. 2007, 373, $572-575$.

[14] H. H. Lara, N. V. Ayala-Nunez, L. C. I. Turrent, C. R. Padilla, World J. Microbiol. Biotechnol. 2010, 26, 615-620.

[15] A. M. Fayaz, K. Balaji, M. Girilal, R. Yadav, P. T. Kalaichevan, R. Venketesan, Nanomedicine 2010, 6, 103-109.

[16] P. Li, J. Li, C. Wu, Q. Wu, J. Li, Nanotechnology 2005, 16, 1912-1917.

[17] J. R. Morones-Ramirez, J. A. Winkler, C. S. Spina, J. J. Collins, Sci. Transl. Med. 2013, 5, 190ra81.

[18] J. P. Loll, P. H. Axelsen, Annu. Rev. Biophys. Biomol. Struct. 2000, 29, 265289.

[19] P. E. Reynolds, Eur. J. Microb. Infect. 1989, 8, 943-950.

[20] J. C. J. Barna, D. H. Williams, Annu. Rev. Microbiol. 1984, 38, 339-357.

[21] J. S. Clement, P. S. Jarrett, Metal Based Drugs 1994, 1, 467-482.

[22] S. Eckhardt, P. S. Brunetto, J. Gagnon, M. Priebe, B. Giese, K. M. Fromm, Chem. Rev. 2013, 113, 4708-4754.

[23] K. M. Fromm, Nat. Chem. 2011, 3, 178.

[24] R. M. Slawson, M. I. van Dyke, H. Lee, J. T. Trevors, Plasmid 1992, 27, 72 79.

[25] C. A. Moyer, L. Brentano, D. L. Gravens, H. W. Margraf, W. W. Monafo, Jr., Arch. Surg. 1965, 90, 812-867.

[26] N. George, J. Faoagali, M. Muller, Burns 1997, 23, 493-495.

[27] J. R. Morones, J. L. Elechiguerra, A. Camacho, K. Holt, J. B. Kouri, J. T. Ramírez, M. J. Yacaman, Nanotechnology 2005, 16, 2346-2353.

[28] C. Baker, A. Pradhan, L. Pakstis, D. J. Pochan, S. I. Shah, J. Nanosci. Nanotechnol. 2005, 5, 244-249.

[29] W.-R. Li, X.-B. Xie, Q.-S. Shi, S.-S. Duan, Y.-S. Ouyang, Y.-B. Chen, BioMetals 2011, 24, 135-141.

[30] J. S. Kim, E. Kuk, K. N. Yu, J.-H. Kim, S. J. Park, H. J. Lee, S. H. Kim, Y. K. Park, Y. H. Park, C.-Y. Hwang, Y.-K. Kim, Y.-S. Lee, D. H. Jeong, M.-H. Cho, Nanomedicine 2007, 3, 95-101.

[31] S. Sadhasivam, P. Shanmugam, K. Yun, Colloids Surf. B 2010, 81, 358 362.

[32] K. Kathiresan, N. M. Alikunhi, S. Pathmanaban, A. Nabikhan, S. Kandasamy, Can. J. Microbiol. 2010, 56, 1050-1059.

[33] J. L. Elechiguerra, J. L. Burt, J. R. Morones, A. Camacho-Bragado, X. Gao, H. H. Lara, M. J. J. Yacaman, J. Nanobiotechnol. 2005, 3, 6.

[34] L. Lu, R. W.-Y. Sun, R. Chen, C.-K. Hui, C.-M. Ho, J. M. Luk, G. K. K. Lau, C.M. Che, Antiviral Ther. 2008, 13, 253-262.

[35] H. H. Lara, N. V. Ayala-Nunez, L. Ixtepan-Turrent, C. Rodriguez-Padilla, J. Nanobiotechnol. 2010, 8, 1-10.

[36] D. Baram-Pinto, S. Shukla, N. Perkas, A. Gedanken, R. Sarid, Bioconjugate Chem. 2009, 20, 1497-1502.

[37] J. P. Guggenbichler, M. Böswald, S. Lugauer, T. Krall, Infection 1999, 27, $\mathrm{S} 16-\mathrm{S} 23$.

[38] K. J. Kim, W. S. Sung, S. K. Moon, J. S. Choi, J. G. Kim, D. G. Lee, J. Microbiol. Biotechnol. 2008, 18, 1482-1484.

[39] I. Sondi, B. Salopek-Sondi, J. Colloid Interface Sci. 2004, 275, 177-182.

[40] M. Yamanaka, K. Hara, J. Kudo, Appl. Environ. Microbiol. 2005, 71, 75897593.

[41] T. V. Slenters, I. Hauser-Gerspach, A. U. Daniels, K. M. Fromm, J. Mater. Chem. 2008, 18, 5359-5362

[42] O. Gordon, T. V. Slenters, P. S. Brunetto, A. E. Villaruz, D. E. Sturdevant, M. Otto, R. Landmann, K. M. Fromm, Antimicrob. Agents Chemother. 2010 $54,4208-4218$ 
[43] T. V. Slenters, J. L. Sagué, P. S. Brunetto, S. Zuber, A. Fleury, L. Mirolo, A. Y. Robin, M. Meuwly, O. Gordon, R. Landmann, A. U. Daniels, K. M Fromm, Materials 2010, 3, 3407-3429.

[44] P. S. Brunetto, T. V. Slenters, K. M. Fromm, Materials 2011, 4, 355-367.

[45] I. Chevrier, J. Sagué, P. S. Brunetto, N. Khanna, Z. Rajacic, K. M. Fromm, Dalton Trans. 2013, 42, 217-231.

[46] K. M. Fromm, J. L. Sagué, A. Y. Robin, Inorg. Chim. Acta 2013, 403, 2-8.

[47] D. L. Boger, Med. Res. Rev. 2001, 21, 356-381.

[48] G. Wang, J. F. Hindler, K. W. Ward, D. A. Bruckner, J. Clin. Microbiol. 2006 44, 3883-3886.

[49] P. S. Brunetto, K. M. Fromm, Chimia 2008, 62, 249-252.

[50] L. O. White, R. Edwards, H. A. Holt, A. M. Lovering, R. G. Finch, D. S. Reeves, J. Antimicrob. Chemother. 1988, 22, 739-745.

[51] H. Liu, H. Yamamoto, J. Wei, D. H. Waldeck, Langmuir 2003, 19, 2378 2387.

[52] M. L. Carman, T. G. Estes, A. W. Feinberg, J. F. Schumacher, W. Wilkerson, L. H. Wilson, M. E. Callow, J. A. Callow, A. B. Brennan, Biofouling 2006 $22,11-21$.

[53] U. Jönsson, B. Ivarsson, I. Lundström, L. Berghem, J. Colloid Interface Sci. 1982, 90, 148-163.

[54] D. E. MacDonald, N. Deo, B. Markovic, M. Stranick, P. Somasundaran, Biomaterials 2002, 23, 1269-1279.

[55] H. Noh, E. A. Vogler, Biomaterials 2006, 27, 5801-5812.

[56] E. Ostuni, R. G. Chapman, R. E. Holmlin, S. Takayama, G. M. Whitesides, Langmuir 2001, 17, 5605-5620.

[57] D. Hanein, B. Geiger, L. Addadi, Langmuir 1993, 9, 1058-1065.

[58] E. M. Harnett, J. Aldermann, T. Wood, Colloids Surf. B 2007, 55, 90-97.

[59] T. G. Ruardy, J.M. Schakenraad, H. C. van der Mei, H. J. Busscher, J. Biomed. Mater. Res. 1995, 29, 1415-1423.

[60] E. M. Hetrick, M. H. Schoenfisch, Chem. Soc. Rev. 2006, 35, 780-789.

[61] M. Schäfer, T. R. Schneider, G. M. Sheldrick, Structure 1996, 4, 1509 1515

[62] C.-C. Yang, C.-C. Lin, J.-W. Liao, S.-K. Yen, Mater. Sci. Eng. C 2013, 33, 2203-2212.

[63] X. Zhang, U. P. Wyss, D. Pichora, M. F. A. Goosen, J. Pharm. Pharmacol. 1994, 46, 718-724.
[64] A. W. Bauer, W. M. M. Kirby, J. C. Sherris, M. Turck, Am. J. Clin. Pathol. $1966,45,493-496$

[65] B. D. Springer, G.-C. Lee, D. Osmon, G. J. Haidukewych, A. D. Hanssen, D. J. Jacofsky, Clin. Orthop. Relat. Res. 2004, 427, 47-51.

[66] C. G. Zalavras, M. J. Patzakis, P. Holtom, Clin. Orthop. Relat. Res. 2004, 427, 86-93.

[67] K. S. Midwood, L. V. Williams, J. E. Schwarzbauer, Int. J. Biochem. Cell Biol. 2004, 36, $1031-1037$

[68] K. Burridge, K. Fath, T. Kelly, G. Nuckolls, C. Turner, Annu. Rev. Cell Biol. $1988,4,487-525$.

[69] K. Burridge, K. Fath, Bioessays 1989, 10, 104-108.

[70] M. Chrzanowska-Wodnicka, K. Burridge, J. Cell Biol. 1996, 133, 1403 1415

[71] K. Anselme, Biomaterials 2000, 21, 667-681.

[72] V. Petit, J.-P. Thiery, Biol. Cell 2000, 92, 477-494.

[73] S. S. Birla, V. V. Tiwari, A. K. Gade, A. P. Ingle, A. P. Yadav, M. K. Rai, Lett Appl. Microbiol. 2009, 48, 173-179.

[74] S. Z. Naqvi, U. Kiran, M. I. Ali, A. Jamal, A. Hameed, S. Ahmed, N. Ali, Int. J. Nanomedicine 2013, 8, 3187-3195.

[75] A. M. Allahverdiyev, K. V. Kon, E. S. Abamor, M. Bagirova, M. Rafailovich Expert Rev. Anti-Infect. Ther. 2011, 9, 1035-1052.

[76] D. Neut, H. van de Belt, I. Stokroos, J. R. van Horn, H. C. van der Mei, H. J. Busscher, J. Antimicrob. Chemother. 2001, 47, 885-891.

[77] B. Thomes, P. Murray, D. Bouchier-Hayes, J. Bone Joint Surg. Br. 2002, 84, $758-760$

[78] D. P. König, J. M. Schierholz, R.-D. Hilgers, C. Bertram, F. Perdreau-Remington, J. Rütt, Langenbecks Arch. Surg. 2001, 386, 328-332.

[79] K. Anagnostakos, P. Hitzler, D. Pape, D. Kohn, J. Kelm, Acta Oethopaedica 2008, 79, 302-307.

[80] S. Herbert, A.-K. Ziebandt, K. Ohlsen, T. Schäfer, M. Hecker, D. Albrecht, R. Novick, F. Götz, Infect. Immun. 2010, 78, 2877-2889.

[81] H. Rohde, S. Frankenberger, U. Zähringer, D. Mack, Eur. J. Cell Biol. 2010, $89,103-111$.

Received: January 30, 2014

Published online on May 2, 2014 